\title{
Flow Behaviour of Aluminium-Based Materials at Ultrahigh Temperatures in the Presence of a Liquid Phase
}

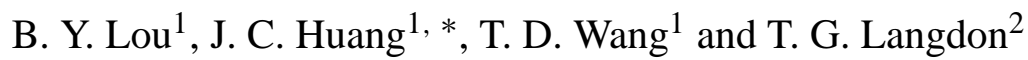 \\ ${ }^{1}$ Institute of Materials Science and Engineering, National Sun Yat-Sen University, Kaohsiung, Taiwan 804, R.O.China \\ ${ }^{2}$ Departments of Aerospace \& Mechanical Engineering and Materials Science, \\ University of Southern California, Los Angeles, CA 90089-1453, USA
}

Experiments were conducted to determine the flow behavior of three materials at ultrahigh temperatures: an Al-6061 composite containing $20 \mathrm{vol} \% \mathrm{SiC}$ whiskers and unreinforced $\mathrm{Al}-6061$ and $\mathrm{Al}-1050$ alloys prepared by casting. Tensile tests were performed at strain rates up to $5 \times 10^{-1} \mathrm{~s}^{-1}$ and over a range of ultrahigh temperatures up to and above the temperatures where there is a small amount of liquid phase. High strain rate superplasticity was achieved in the composite material but not in the unreinforced alloys. For all three materials, it is shown that the true activation energy for flow changes from values of $<200 \mathrm{~kJ} \mathrm{~mol}^{-1}$ at the lower temperatures where there is no liquid phase to exceptionally high values in the presence of a liquid phase: these values are up to $>1000 \mathrm{~kJ} \mathrm{~mol}^{-1}$ for the composite and the Al-1050 alloy. It is concluded that exceptionally high activation energies are an inherent feature of flow in materials containing a small amount of discontinuous liquid at temperatures immediately above the onset of partial melting.

(Received October 25, 2001; Accepted January 9, 2002)

Keywords: high temperature deformation behavior, liquid phase, aluminum, superplasticity

\section{Introduction}

High strain rate superplasticity (HSR SP) is defined formally as the occurrence of large tensile ductilities at strain rates at and above $10^{-2} \mathrm{~s}^{-1}$. To date, there are numerous reports of HSR SP in a wide range of metallic alloys, metal matrix composites (MMCs) prepared by powder metallurgy and mechanically alloyed materials: for convenience, much of this work has been summarized and tabulated. ${ }^{1)}$

It is found through experiments on HSR SP in MMCs that logarithmic plots of strain rate versus stress generally exhibit a marked curvature such that the slope increases at the lower stress levels. This curvature leads to an increase with decreasing stress in the value of the apparent stress exponent, $n_{\mathrm{a}}$, and it is found in addition that the apparent activation energy for creep, $Q_{\mathrm{a}}$, also increases at the lower stresses. Results of this type are generally interpreted by invoking a threshold stress, $\sigma_{\text {th }}$, representing a lower limiting stress for measurable flow, and then considering flow to occur under an effective stress, $\sigma^{*}$, defined as $\left(\sigma-\sigma_{\text {th }}\right)$ where $\sigma$ is the applied stress. When experimental data are re-analyzed in terms of $\left(\sigma-\sigma_{\text {th }}\right)$, the estimated values of the true stress exponent, $n$, are generally close to $\sim 2$ which is consistent with conventional superplasticity. ${ }^{2,3)}$ However, even when the temperature dependences of both the threshold stress and the elastic modulus of the material are incorporated into the analysis, the values estimated for the true activation energy, $Q_{\mathrm{t}}$, are invariably exceptionally high. For example, the reported true activation energy was $\sim 774 \mathrm{~kJ} \mathrm{~mol}^{-1}$ in an Al-6061 alloy: ${ }^{4)}$ since this MMC has aluminum alloy matrix, it is reasonable to anticipate that $Q_{\mathrm{t}}$ should be close to the value for lattice self-diffusion in pure $\mathrm{Al}\left(\sim 142 \mathrm{~kJ} \mathrm{~mol}^{-1}\right){ }^{5)}$

A series of elegant experiments has led to significant progress in interpreting the high values of the activation energies associated with HSR SP. ${ }^{6-12)}$ First, experiments revealed

*Corresponding author: E-mail address: jacobc@mail.nsysu.edu.tw the occurrence of partial melting in Al-based MMCs both at the matrix/reinforcement interfaces and at the matrix grain boundaries when the temperature was close to that associated with optimum superplasticity. ${ }^{6-8,10)}$ And it was demonstrated subsequently, through an analysis of extensive HSR SP data for several MMCs, that the activation energy for flow changes, essentially at the temperature associated with the onset of partial melting, from a value close to that for lattice self-diffusion in pure aluminum to a very high value of $>800 \mathrm{~kJ} \mathrm{~mol}^{-1}$.9) Later experiments showed there were three distinct ranges of deformation in these MMCs depending upon the testing temperature: (1) at the lower temperatures there was no liquid phase and deformation occurred through conventional superplasticity with an activation energy close to that for lattice self-diffusion, (2) at temperatures immediately above the onset of partial melting the semi-solid contained a discontinuous intergranular liquid phase and deformation occurred with a very high activation energy (up to $>1000 \mathrm{~kJ} \mathrm{~mol}^{-1}$ ) and (3) at even higher temperatures the semi-solid contained a continuous liquid phase and the activation energy for flow was low $\left(\sim 56 \mathrm{~kJ} \mathrm{~mol}^{-1}\right){ }^{11)}$ Experiments on the deformation of an $\mathrm{Al}-5 \% \mathrm{Mg}$ alloy in a semi-solid state confirmed the occurrence of regions having high and low activation energies at temperatures above the onset of partial melting and they showed further that, when the thickness of the liquid layer is incorporated into the analysis, the activation energy in the presence of a continuous liquid phase is approximately equal to that anticipated for the viscosity of molten aluminum $\left(\sim 16.5 \mathrm{~kJ} \mathrm{~mol}^{-1}\right) .{ }^{12)}$

The present experiments were motivated by these earlier results and they were initiated in order to extend the observations of ultrahigh temperature deformation to include materials prepared by casting. The tests were conducted with two specific objectives. First, to compare the high temperature flow of an Al-based MMC and a cast material having the same composition as the matrix alloy. Second, to exam- 
ine the flow at ultrahigh temperatures of a cast aluminum of commercial purity.

\section{Experimental Details}

Three different materials were used in these experiments. An Al-6061 composite containing 20 vol\% SiC whiskers was obtained from The Advanced Materials Corporation (Greer, SC, USA) with the whiskers having diameters of $\sim 0.5 \mu \mathrm{m}$ and lengths of $\sim 10 \mu \mathrm{m}$ : henceforth, this material is designated $6061 / \mathrm{SiC}_{\mathrm{w}}$. Two commercial cast alloys, an Al6061 alloy and an Al-1050 alloy, were obtained from the CS Aluminum Corporation (Kaohsiung, Taiwan) where the latter alloy is an industrial-grade pure aluminum. Table 1 lists the chemical compositions of these three materials. The $6061 / \mathrm{SiC}_{\mathrm{w}}$ composite was fabricated by powder metallurgy processing followed by extrusion and rolling at $\sim 400^{\circ} \mathrm{C}$ to give a fine grain size of $\sim 0.5-1.0 \mu \mathrm{m}:^{4)}$ as will be demonstrated, this material exhibits HSR SP. The as-cast Al6061 and Al-1050 alloys were received as plates in a nonsuperplastic condition and they were subjected to thermomechanical processing, including extrusion at $\sim 300^{\circ} \mathrm{C}$ with an extrusion ratio of $\sim 42$ and cold rolling to a final thickness of $2 \mathrm{~mm}$, to give similar initial grain sizes in the range of $\sim 0.5-1.0 \mu \mathrm{m}$ : the experiments show these cast alloys do not exhibit HSR SP.

Tensile samples were machined from each material with gauge lengths of $5.5 \mathrm{~mm}$ and with the loading axes parallel to the rolling direction. The tensile tests were conducted using testing machines equipped with three-zone furnaces and operating at constant rates of cross-head displacement. The initial strain rates were in the range from $10^{-4}$ to $10 \mathrm{~s}^{-1}$ for all materials and the tests were performed over a temperature range from 500 to $655^{\circ} \mathrm{C}$ with the testing temperatures controlled to within $\pm 2^{\circ} \mathrm{C}$. These temperatures were selected so that testing was extended to within the region where there is a liquid phase in each material. Thus, the incipient partial melting temperature, $T_{\mathrm{i}}$, was measured from the onset of the sharp endothermic peak as $\sim 584^{\circ} \mathrm{C}$ for this $6061 / \mathrm{SiC}_{\mathrm{w}}$ composite ${ }^{4)}$ and the solidus temperatures, $T_{\mathrm{s}}$, for the Al-6061 and Al-1050 alloys are $\sim 582^{\circ} \mathrm{C}^{13)}$ and $\sim 646^{\circ} \mathrm{C},{ }^{14)}$ respectively.

The microstructures of each material were examined both before and after tensile testing. Samples were mechanically milled, polished with diamond paste and examined using a Nikon Microphot-FXL optical microscope or a JEOL 6400 scanning electron microscope. Grain boundaries were revealed using an aqueous etching solution containing $10 \% \mathrm{HF}$ and $10 \% \mathrm{HCl}$ by volume. The fracture surfaces of some of the deformed specimens were also characterized using scanning electron microscopy.

Table 1 Chemical compositions of the three materials (in mass\%).

\begin{tabular}{ccccccccc}
\hline Material & $\mathrm{Mg}$ & $\mathrm{Si}$ & $\mathrm{Cu}$ & $\mathrm{Fe}$ & $\mathrm{Cr}$ & $\mathrm{Mn}$ & $\mathrm{Zn}$ & $\mathrm{Al}$ \\
\hline $6061 / \mathrm{SiC}_{\mathrm{w}}$ & 0.93 & 0.73 & 0.28 & 0.26 & 0.07 & -- & 0.04 & Bal. \\
$\mathrm{Al}-6061$ & 1.00 & 0.60 & 0.27 & 0.70 & 0.20 & -- & 0.20 & Bal. \\
$\mathrm{Al}-1050$ & 0.05 & 0.25 & 0.05 & 0.04 & -- & 0.05 & 0.05 & Bal. \\
\hline
\end{tabular}

\section{Results}

\subsection{Mechanical behavior at ultrahigh temperatures}

Typical plots of true stress versus strain are shown in Fig. 1 for the three different materials when testing at a temperature of $550^{\circ} \mathrm{C}$. These curves are generally representative of those obtained at the other temperatures and they reveal extensive strain hardening in the MMC at all strain rates and in the two cast alloys for the tests conducted at strain rates at and above $\sim 10^{-1} \mathrm{~s}^{-1}$.

For each material, the true stress was measured at a strain of $\sim 0.4$ and the data were plotted logarithmically as stress versus strain rate as shown in Fig. 2: a strain of 0.4 was selected because it is close to the flow stress in the two cast alloys and it was found that the strain selected for these stress measurements had relatively little effect on the subsequent analysis for the $6061 / \mathrm{SiC}_{\mathrm{w}}$ composite. Inspection of Fig. 2 leads to three conclusions. First, the stresses in $6061 / \mathrm{SiC}_{\mathrm{w}}$ are lower than in the unreinforced Al-6061 matrix alloy at all strain rates and
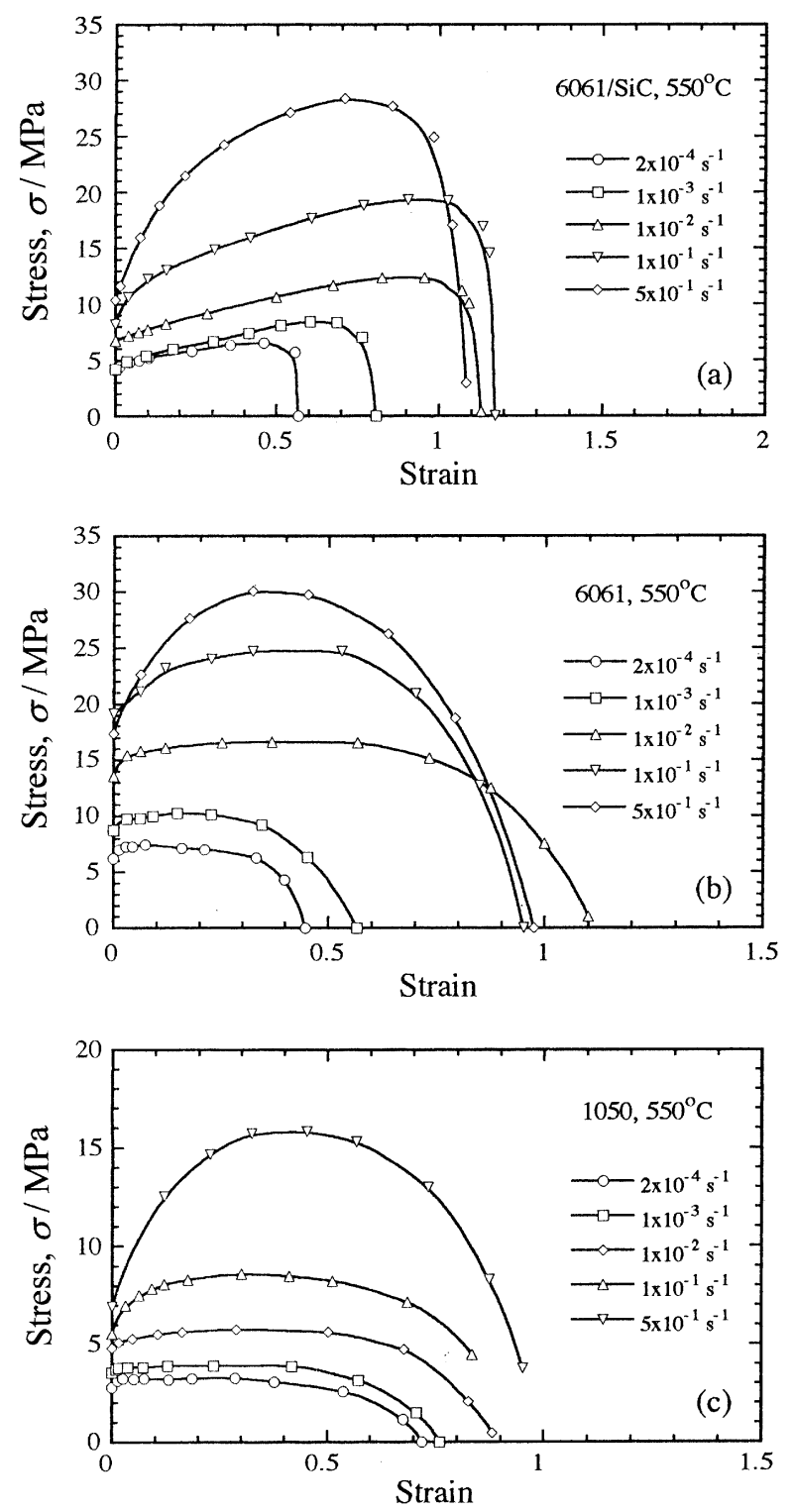

Fig. 1 True stress versus strain for tests conducted at $550^{\circ} \mathrm{C}$ on (a) $6061 / \mathrm{SiC}_{\mathrm{W}}$, (b) Al-6061 and (c) Al-1050. 

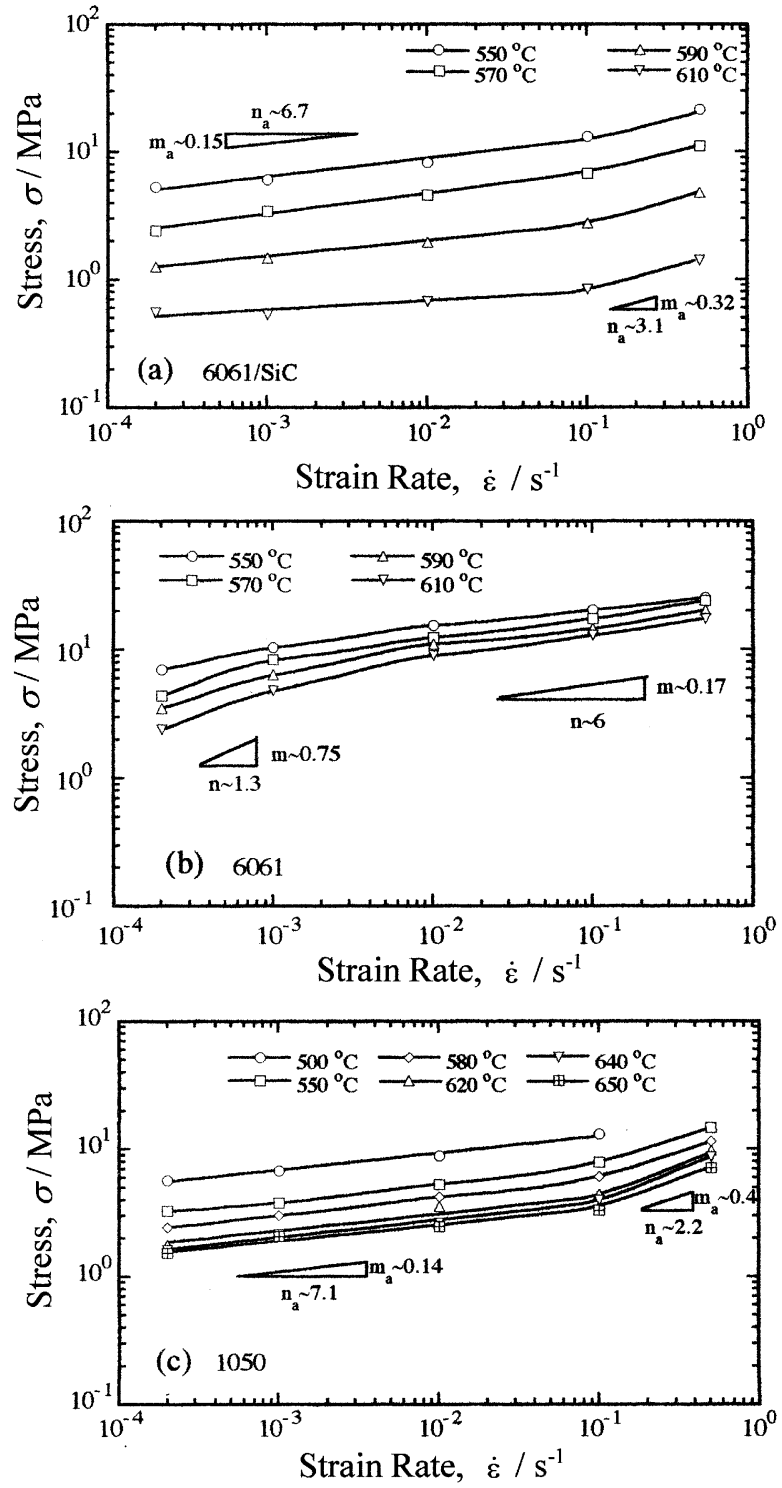

Fig. 2 True stress at $\varepsilon \approx 0.4$ versus strain rate for (a) $6061 / \mathrm{SiC}_{\mathrm{w}}$, (b) Al-6061 and (c) Al-1050.

temperatures; this is consistent with earlier reports for similar materials. ${ }^{15,16)}$ Second, the values of the apparent stress exponents, $n_{\mathrm{a}}$, are in the range of $\sim 5-7$ over a wide range of strain rates for each material but there is evidence of a reduction in the values of $n_{\mathrm{a}}$ at the very highest strain rates, above $\sim 10^{-1} \mathrm{~s}^{-1}$, in $6061 / \mathrm{SiC}_{\mathrm{w}}$ and in the Al-1050 alloy. Third, there is also evidence for a decrease in $n_{\mathrm{a}}$ to $\sim 1.3$ in the Al6061 alloy at the lowest strain rates and with testing temperatures at and above $570^{\circ} \mathrm{C}$. By contrast, the value of $n_{\mathrm{a}}$ is close to $\sim 6$ for this alloy over the entire strain rate range at the lowest testing temperature of $550^{\circ} \mathrm{C}$. The typical values of apparent strain rate sensitivity $m_{\mathrm{a}}$ or stress exponent $n_{\mathrm{a}}$, as well as the tensile elongation of these three materials at the high temperature and high strain rate regime are listed in Table 2.

Representative values of the measured elongations to failure are plotted in Fig. 3 for $6061 / \mathrm{SiC}_{\mathrm{w}}$ and $\mathrm{Al}-6061$ at $590^{\circ} \mathrm{C}$ and $\mathrm{Al}-1050$ at $640^{\circ} \mathrm{C}$ where the ductilities are close to optimum. It was found that the $6061 / \mathrm{SiC}_{\mathrm{w}}$ composite exhibited HSR SP and high elongations were recorded at strain rates
Table 2 Typical values of the apparent strain rate sensitivity, $m_{\mathrm{a}}$ (and $n_{\mathrm{a}}=1 / m_{\mathrm{a}}$ ), and tensile failure elongation for the three materials at high temperatures and high strain rates.

\begin{tabular}{cccccc}
\hline Material & $T /{ }^{\circ} \mathrm{C}$ & $\dot{\varepsilon} / \mathrm{s}^{-1}$ & $m_{\mathrm{a}}$ & $n_{\mathrm{a}}$ & $e(\%)$ \\
\hline $6061 / \mathrm{SiC}_{\mathrm{w}}$ & $550-610$ & $1 \times 10^{-1}$ & $\sim 0.32$ & $\sim 3$ & $\sim 200-400$ \\
6061 & $550-610$ & $2 \times 10^{-2}$ & $\sim 0.17$ & $\sim 6$ & $\sim 150-200$ \\
1050 & $500-650$ & $2 \times 10^{-2}$ & $\sim 0.14$ & $\sim 7$ & $\sim 150-200$ \\
\hline
\end{tabular}

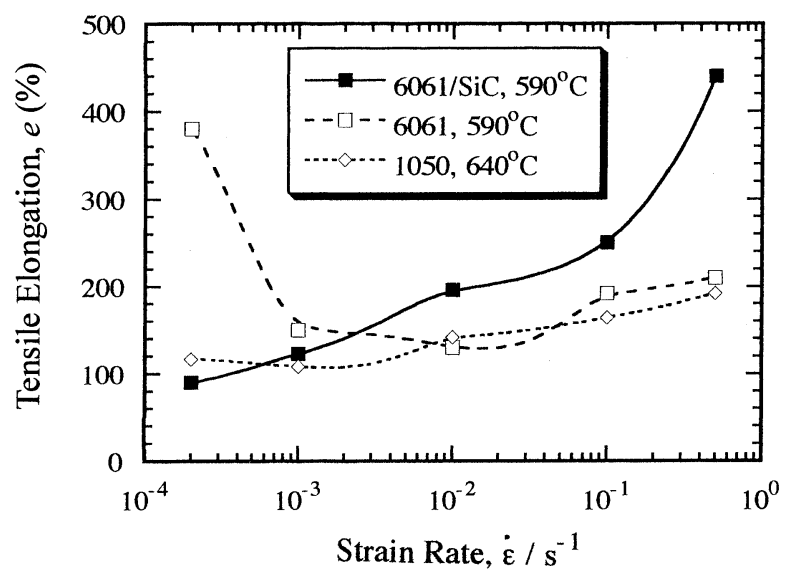

Fig. 3 Elongation to failure versus strain rate for the three materials at temperatures where the ductilities are close to optimum.

$>10^{-1} \mathrm{~s}^{-1}$ when testing at $590-610^{\circ} \mathrm{C}$ which is above the incipient melting temperature of $584^{\circ} \mathrm{C}$. For the composite, the highest recorded elongation was $480 \%$ at a strain rate of $5 \times 10^{-1} \mathrm{~s}^{-1}$ with test temperatures of 590 and $600^{\circ} \mathrm{C}$ but the elongations were reduced to $<20 \%$ at all strain rates at the even higher temperature of $620^{\circ} \mathrm{C}$. For the unreinforced $\mathrm{Al}-$ 6061 alloy, the maximum recorded elongation was $\sim 400 \%$ at 590 and $610^{\circ} \mathrm{C}$ with a low strain rate of $2 \times 10^{-4} \mathrm{~s}^{-1}$. This alloy therefore fails to exhibit HSR SP but the result is consistent with an earlier report showing superplastic elongations in this alloy at $590^{\circ} \mathrm{C}$ with a strain rate of $\sim 10^{-4} \mathrm{~s}^{-1}$. 13) However, the elongations of this alloy were reduced at $620^{\circ} \mathrm{C}$ to only $\sim 18 \%$ and $\sim 25 \%$ using strain rates of $2 \times 10^{-4}$ and $5 \times 10^{-1} \mathrm{~s}^{-1}$, respectively. The highest tensile elongations recorded for the Al-1050 alloy were $\sim 200 \%$ at temperatures of 640 and $650^{\circ} \mathrm{C}$ with a strain rate of $5 \times 10^{-1} \mathrm{~s}^{-1}$, with macroscopic melting occurring at the even higher testing temperature of $655^{\circ} \mathrm{C}$ where the elongation was reduced to $\sim 40 \%$. The absence of HSR SP in the unreinforced Al1050 alloy at the faster strain rates suggests that the increase in $m_{\mathrm{a}}$ evident in Fig. 2(c) at strain rates above $\sim 10^{-1} \mathrm{~s}^{-1}$ may be associated with the advent of power-law breakdown.

\subsection{Grain structures at high temperatures}

Observations after deformation at these high temperatures revealed the occurrence of pronounced grain growth in the two unreinforced alloys and there were larger grain sizes recorded within the gauge sections. Since the stress-strain rate data plotted in Fig. 2 were obtained from the stress-strain curves at a true strain of $\sim 0.4$, optical microscopy was used to examine representative grain structures within the gauge lengths of samples where the tests were terminated at strains of $\sim 0.4$. Two examples are shown in Fig. 4 for the Al-6061 
alloy after testing at $1 \times 10^{-1} \mathrm{~s}^{-1}$ at the two temperatures of (a) $570^{\circ} \mathrm{C}$ and (b) $610^{\circ} \mathrm{C}$, respectively, where the latter temperature is above the solidus temperature of $582^{\circ} \mathrm{C}$. The absence of unusually thick grain boundaries in Fig. 4(b) suggests that only a limited amount of liquid phase is present in this alloy at this temperature.

The mean linear intercept grain size, $\bar{L}$, was measured for each material at each testing temperature at a strain of $\sim 0.4$ and then converted to the spatial grain size, $d(=1.7 \bar{L})$. Figure 5 plots the variation of the measured values of $d$ against the testing temperature. It is apparent that the grain
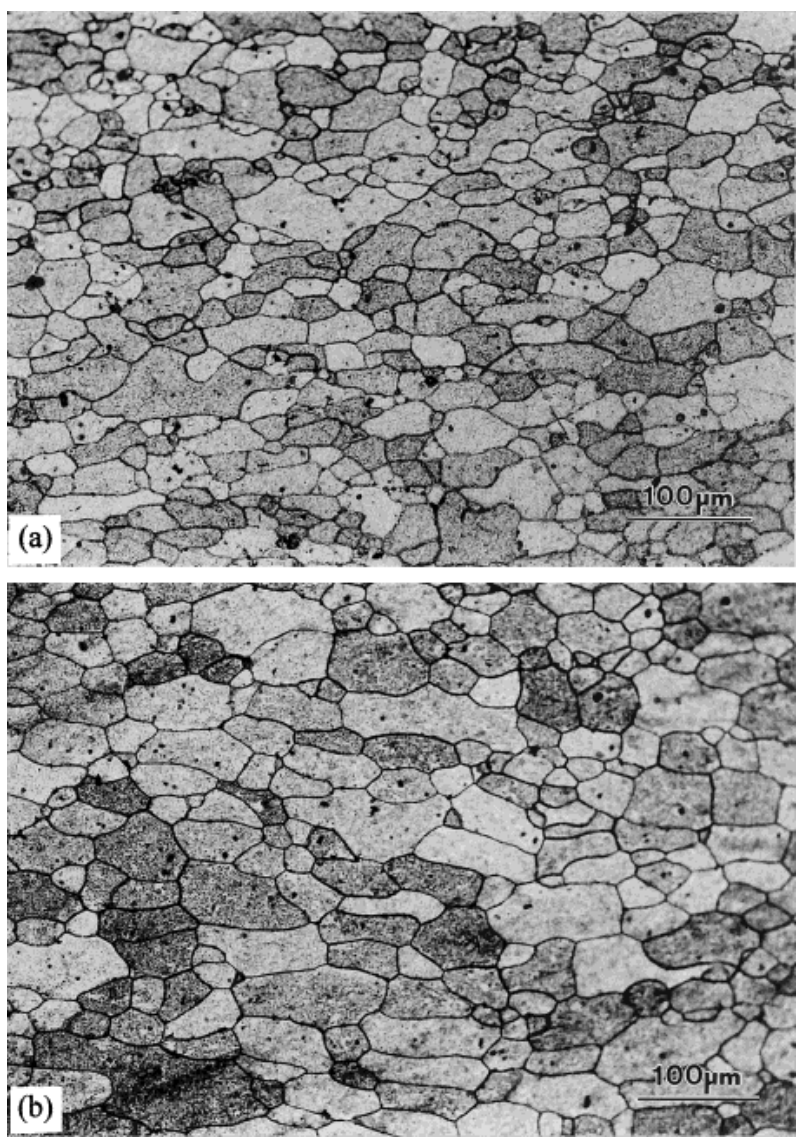

Fig. 4 Optical micrographs showing the grain structures in the Al-6061 alloy at a true strain of $\sim 0.4$ when testing with a strain rate of $1 \times 10^{-1} \mathrm{~s}^{-1}$ at (a) $570^{\circ} \mathrm{C}$ and (b) $610^{\circ} \mathrm{C}$.

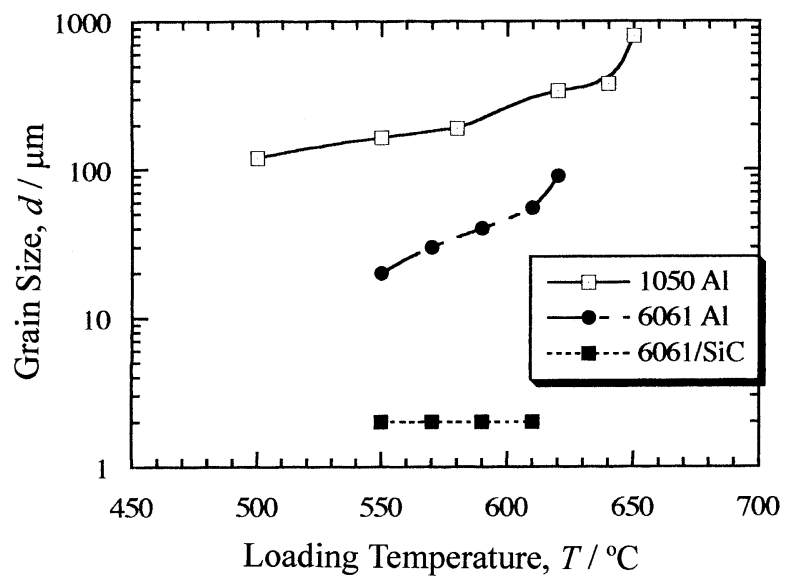

Fig. 5 Spatial grain size measured at a true strain of $\sim 0.4$ versus testing temperature. size remains fairly stable at $\sim 2.0 \mu \mathrm{m}$ over the temperature range from 550 to $610^{\circ} \mathrm{C}$ for the $6061 / \mathrm{SiC}_{\mathrm{w}}$ composite but $d$ increases from $\sim 20 \mu \mathrm{m}$ at $550^{\circ} \mathrm{C}$ to $\sim 90 \mu \mathrm{m}$ at $620^{\circ} \mathrm{C}$ for the Al-6061 alloy and from $\sim 120 \mu \mathrm{m}$ at $500^{\circ} \mathrm{C}$ to $\sim 800 \mu \mathrm{m}$ at $650^{\circ} \mathrm{C}$ for the $\mathrm{Al}-1050$ alloy. The presence of these large grain sizes in the two cast alloys at these high temperatures demonstrates the instability of the ultrafine initial microstructure and this instability explains the consequent absence of HSR SP in these two materials.

\subsection{Fracture characteristics}

All of the $6061 / \mathrm{SiC}_{\mathrm{w}}$ specimens fractured through the development of internal cavities. At testing temperatures above $T_{\mathrm{i}}$, long filaments were visible on the fracture surfaces. An example is shown in Fig. 6(a) for a sample tested at $590^{\circ} \mathrm{C}$ at a strain rate of $1 \times 10^{-1} \mathrm{~s}^{-1}$ : similar observations have been reported in other investigations. ${ }^{11,17)}$ For the Al-6061 alloy, samples failed by cavitation at the lower strain rates $\left(\leq 10^{-2} \mathrm{~s}^{-1}\right)$ but there was severe necking at high strain rates $\left(\geq 10^{-1} \mathrm{~s}^{-1}\right)$. At $620^{\circ} \mathrm{C}$, the elongations in this alloy were very low and there was evidence for brittle failure due to liquid phase decohesion; an example is shown in Fig. 6(b) for a sample tested at $620^{\circ} \mathrm{C}$ using a strain rate of $2 \times 10^{-4} \mathrm{~s}^{-1}$ where failure occurred at an elongation of $18 \%$. All specimens of the Al-1050 alloy failed by necking at all testing temperatures.
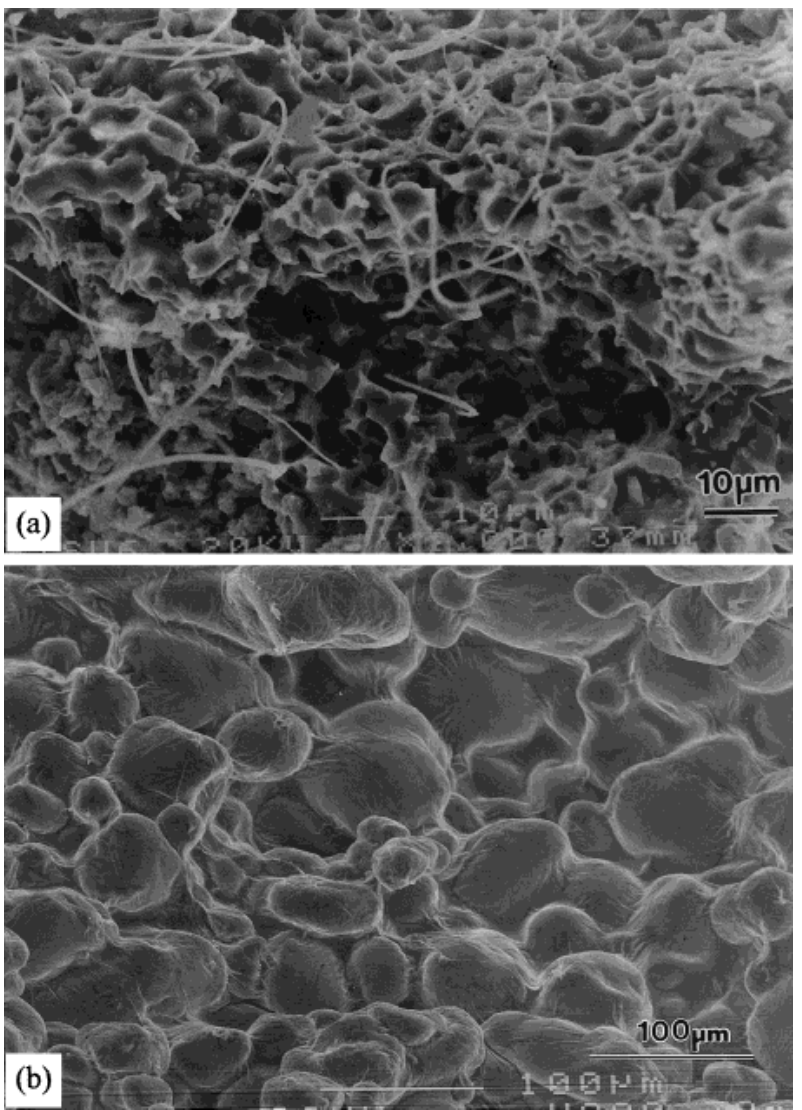

Fig. 6 SEM micrographs of the fracture surfaces: (a) $6061 / \mathrm{SiC}_{\mathrm{w}}$ tested at $590^{\circ} \mathrm{C}$ at a strain rate of $1 \times 10^{-1} \mathrm{~s}^{-1}$ showing the presence of long filaments and (b) Al-6061 tested at $620^{\circ} \mathrm{C}$ at a strain rate of $2 \times 10^{-4} \mathrm{~s}^{-1}$ showing liquid phase decohesion along the grain boundaries. 


\section{Discussion}

\subsection{Values of the true stress exponent, $n$}

The curvature evident in Fig. 2(a) for $6061 / \mathrm{SiC}_{\mathrm{w}}$ is typical of many MMCs ${ }^{18)}$ and it is generally interpreted in terms of the presence of a threshold stress, $\sigma_{\text {th }}$. The individual values of the threshold stresses may be estimated at each testing temperature either by plotting the datum points on linear axes in the form of the strain rate raised to the power of $1 / n$ against the applied stress, where $\mathrm{n}$ is the value estimated for the true stress exponent, ${ }^{19)}$ or, when the experimental data extend over $>5$ orders of magnitude of strain rate, by directly extrapolating the data to strain rates where the stress exponent becomes infinite. ${ }^{20)}$ In the present investigation, the values of $\sigma_{\text {th }}$ were estimated using the former procedure and plots were constructed for values of $\mathrm{n}$ in the range from 1.5 to 5 . It was found that the best linear fit was achieved when using $n=2$ and the relevant plot is shown in Fig. 7(a) for the four testing temperatures. The values estimated for $\sigma_{\text {th }}$ using this procedure were $\sim 5.4, \sim 2.9, \sim 1.3$ and $\sim 0.5 \mathrm{MPa}$ at testing temperatures of $550,570,590$ and $610^{\circ} \mathrm{C}$, respectively. The value of $n=2$ is consistent with HSR SP in other MMCs ${ }^{21)}$ and it suggests that deformation occurs by conventional superplasticity. ${ }^{2,3)}$ Using these values of $\sigma_{\text {th }}$, Fig. 7(b) shows the experimental data replotted logarithmically as strain rate versus the effective stress, $\left(\sigma-\sigma_{\text {th }}\right)$.

For the 6061 alloys, the experimental data in Fig. 2 are not consistent with the presence of a threshold stress and it is reasonable to conclude that, as in conventional power-law creep, the value of $n$ is close to 6 . The extractions of true stress exponent and threshold stress for the 1050 alloy are depicted in Fig. 8. It is found that $n$ is close to 5 and the extracted $\sigma_{\text {th }}$ values are scattered within a low stress level within $0.5-1 \mathrm{MPa}$.

\subsection{Values of the true activation energy, $Q_{\mathrm{t}}$}

The apparent activation energies, $Q_{\mathrm{a}}$, were estimated by plotting, on semi-logarithmic axes, the values of the appropriate stresses against $1 / n R T$, where $R$ is the gas constant and $T$ is the absolute temperature. The results are shown in Fig. 9. It is convenient to consider separately the $6061 / \mathrm{SiC}_{\mathrm{w}}$ composite and the two cast alloys.

\subsubsection{1/ $\mathrm{SiC}_{\mathrm{w}}$}

The effective stresses were used in plotting Fig. 9(a) for $6061 / \mathrm{SiC}_{\mathrm{w}}$ with a stress exponent of $n=2$ from Fig. 7 (b) and a high strain rate of $1 \times 10^{-1} \mathrm{~s}^{-1}$. The values estimated for $Q_{\mathrm{a}}$ are indicated in Fig. 9(a) and they increase from $\sim 190 \mathrm{~kJ} \mathrm{~mol}^{-1}$ at temperatures up to $570^{\circ} \mathrm{C}$ to $\sim 600 \mathrm{~kJ} \mathrm{~mol}^{-1}$ from 570 to $590^{\circ} \mathrm{C}$ and to $\sim 1030 \mathrm{~kJ} \mathrm{~mol}^{-1}$ above $590^{\circ} \mathrm{C}$. Thus, it is apparent that the activation energy begins to increase in the vicinity of the incipient melting temperature of $584^{\circ} \mathrm{C}$ and $Q_{\mathrm{a}}$ becomes exceptionally high at temperatures immediately above $T_{\mathrm{i}}$. All of these values for $Q_{\mathrm{a}}$, including at the lowest temperatures, are higher than the activation energy for self-diffusion in pure $\mathrm{Al}(\sim 142 \mathrm{~kJ} / \mathrm{mol}){ }^{5)}$

The apparent activation energy, $Q_{\mathrm{a}}$, may be corrected to give the true activation energy, $Q_{\mathrm{t}}$, by incorporating into the analysis the temperature dependence of both Young's modulus of elasticity, $E$, and the apparent stress exponent, $n_{\mathrm{a}}$. The
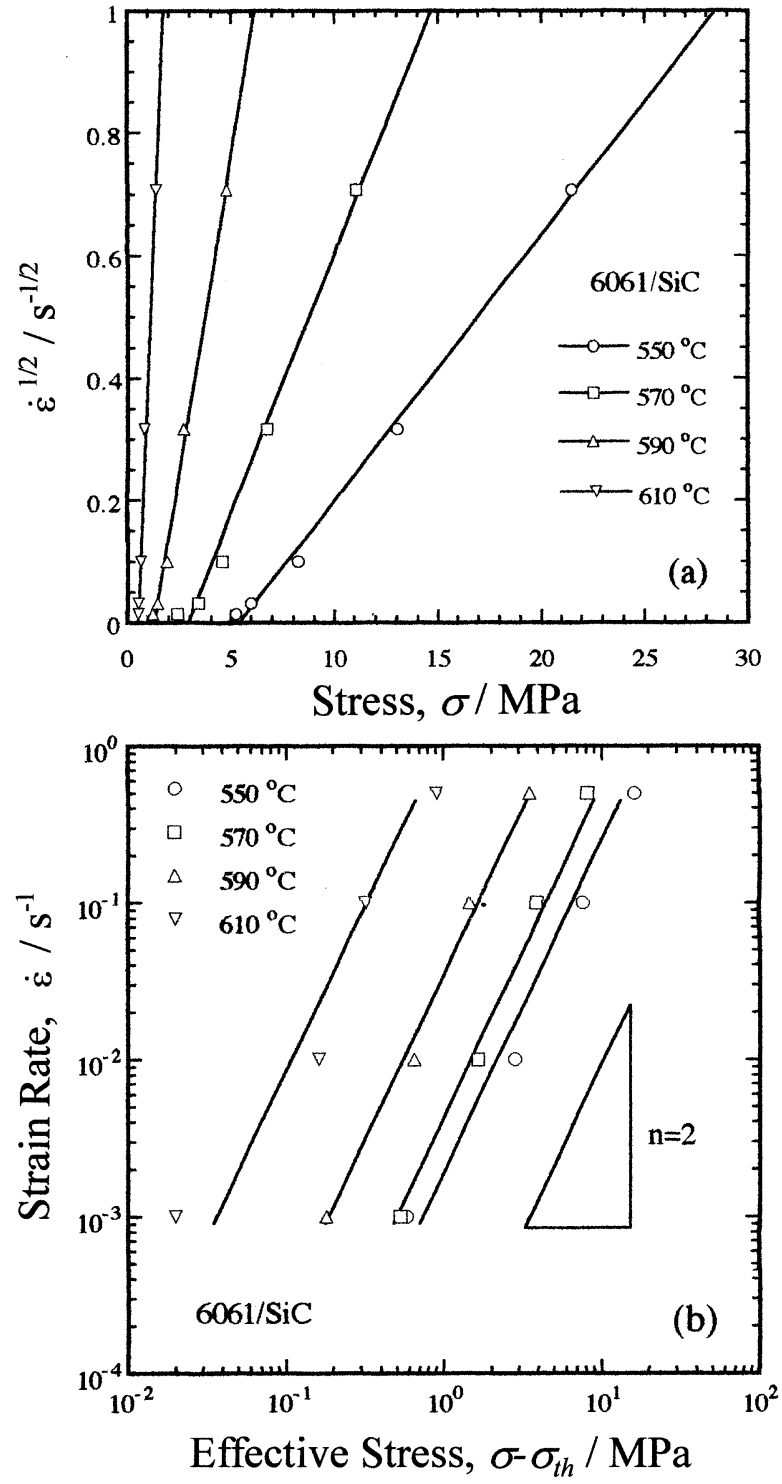

Fig. 7 (a) Procedure for estimating the values of the threshold stresses using $n=2$, and (b) strain rate versus effective stress for $6061 / \mathrm{SiC}_{\mathrm{W}}$.

precise relationship between $Q_{\mathrm{t}}$ and $Q_{\mathrm{a}}$ is given by ${ }^{22)}$

$$
Q_{\mathrm{t}}=Q_{\mathrm{a}}+R T+\frac{(n-1) R T^{2}}{E} \frac{\partial E}{\partial T}+R T^{2} \ln \sigma \frac{\partial n_{\mathrm{a}}}{\partial T} .
$$

Taking the value reported for $\partial E / \partial T$ for pure $\mathrm{Al},{ }^{5)}$ it is found that the second term on the right side of the equality sign in eq. (1) changes the measured activation energy by only approximately +5 to $+8 \mathrm{~kJ} \mathrm{~mol}^{-1}$, the third term has a value of the order of -5 to $-20 \mathrm{~kJ} \mathrm{~mol}^{-1}$ and the last term is essentially negligible at the high strain rates used in these tests. Therefore, the calculated values for the true activation energies become, with increasing temperature, $\sim 190, \sim 595$ and $\sim 1000 \mathrm{~kJ} \mathrm{~mol}^{-1}$ for the three regions shown in Fig. 9(a). These values of $Q_{\mathrm{t}}$ are significantly higher than anticipated for an Al-based MMC but they are consistent with reports of an activation energy of $\sim 1033 \mathrm{~kJ} \mathrm{~mol}^{-1}$ in the HSR SP of a 6061 composite reinforced with $\mathrm{Si}_{3} \mathrm{~N}_{4}$ particulates and tested at temperatures where there is a semi-solid state. ${ }^{11)}$ The comparisons of the current true activation energy with previously reported data ${ }^{4,6,11,12)}$ are presented in Table 3. 

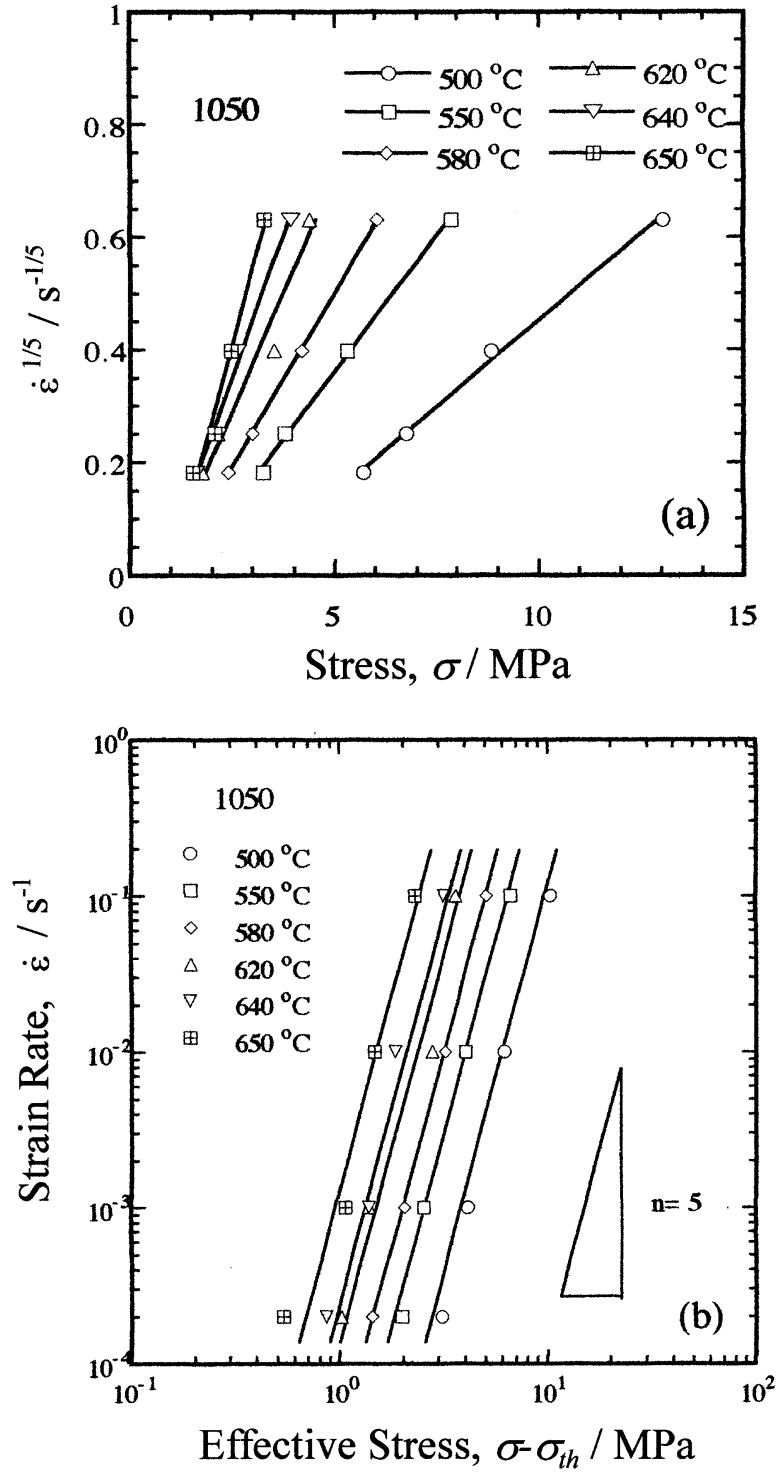

Fig. 8 (a) Procedure for estimating the values of the threshold stresses using $n=5$, and (b) strain rate versus effective stress for Al-1050.

The very high activation energies, which are a consistent feature of HSR SP in MMCs, may arise in part because of an additional temperature dependence which is introduced through the effect of load transfer. ${ }^{21)}$ When load transfer is incorporated into the analysis, the strain rate may be expressed in the form ${ }^{23)}$

$$
\dot{\varepsilon}=\frac{A D E b}{k T}\left(\frac{b}{d}\right)^{p}\left(\frac{(1-\alpha)\left(\sigma-\sigma_{\mathrm{th}}\right)}{E}\right)^{n},
$$

where $D$ is the diffusion coefficient, $b$ is the Burgers vector, $k$ is Boltzmann's constant, $p$ is the exponent of the inverse grain size, $\alpha$ is the load transfer coefficient and $A$ is a dimensionless constant. In the presence of load transfer, it follows that eq. (1) becomes

$$
\begin{aligned}
Q_{\mathrm{t}}= & Q_{\mathrm{a}}+R T+\frac{(n-1) R T^{2}}{E} \frac{\partial E}{\partial T} \\
& +R T^{2} \ln \sigma \frac{\partial n_{\mathrm{a}}}{\partial T}+\frac{n R T^{2}}{1-\alpha} \frac{\partial \alpha}{\partial T} .
\end{aligned}
$$

In order to make use of eq. (3), it is necessary to es-
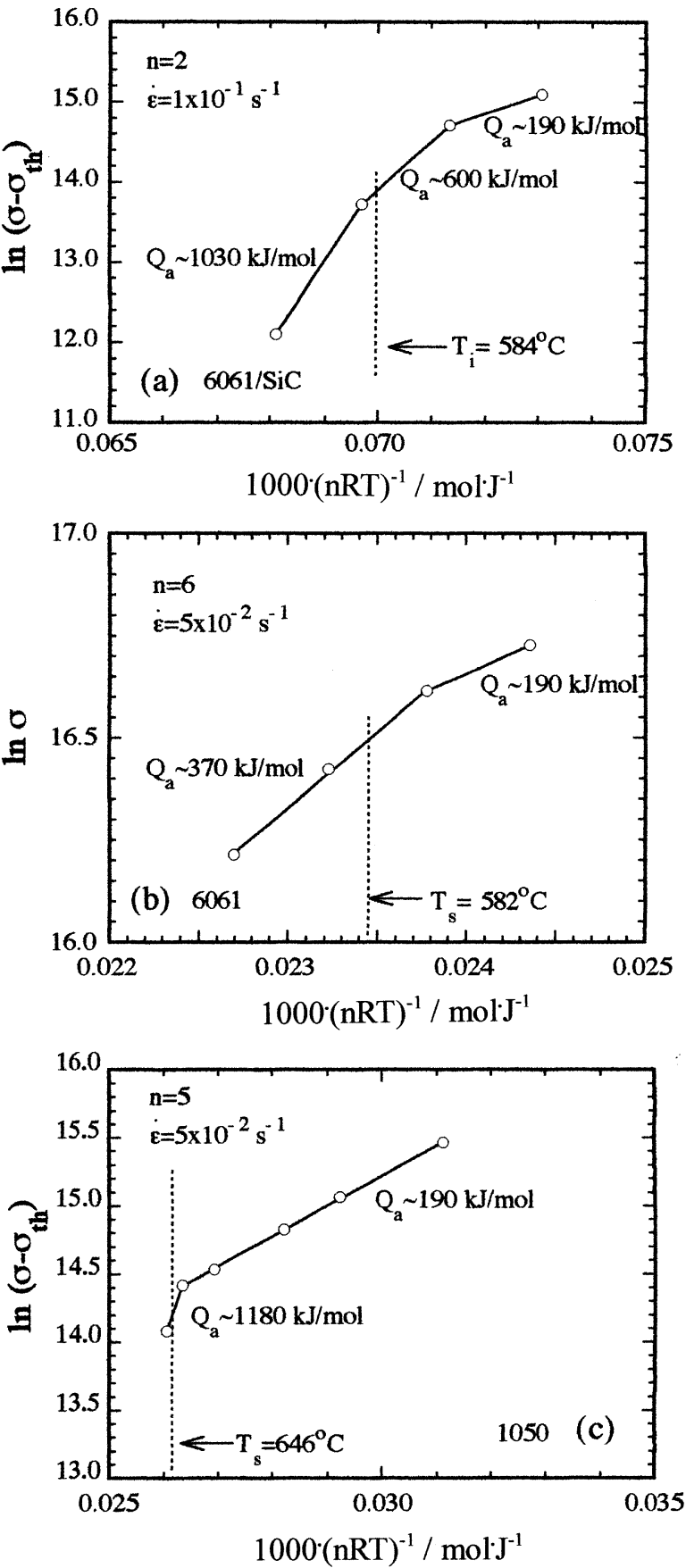

Fig. 9 Estimates of the apparent activation energies for (a) $6061 / \mathrm{SiC}_{\mathrm{w}}$, (b) Al-6061 and (c) Al-1050. The unit used for $\sigma$ is Pa.

timate the relevant values for $\alpha$. The preceding analysis demonstrated that $n=2$ for $6061 / \mathrm{SiC}_{\mathrm{w}}$, thereby suggesting that grain boundary sliding in superplasticity is the major deformation process. A detailed analysis of extensive data for superplasticity led to the development of two different phenomenological relationships where superplasticity is controlled either by lattice diffusion or by grain boundary diffusion, respectively. ${ }^{24)}$ These two relationships are

$$
\dot{\varepsilon}=6.4 \times 10^{9}\left(\frac{D_{1}}{d^{2}}\right)\left(\frac{\sigma}{E}\right)^{2}
$$


Table 3 Estimated true values of $n$ and $Q$ for various aluminum alloys and composites.

\begin{tabular}{cccccl}
\hline Material & $T /{ }^{\circ} \mathrm{C}$ & $\dot{\varepsilon} / \mathrm{s}^{-1}$ & $n$ & $Q_{\mathrm{t}} / \mathrm{kJ} \mathrm{mol}^{-1}$ & Reference \\
\hline $6061 / \mathrm{SiC}_{\mathrm{w}}$ & $500-550$ & $1 \times 10^{-1}$ & 2 & 190 & This study \\
& $550-590$ & $1 \times 10^{-1}$ & 2 & 595 & \\
& $590-610$ & $1 \times 10^{-1}$ & 2 & 1000 & \\
6061 & $500-580$ & $5 \times 10^{-2}$ & 6 & 185 & This study \\
& $580-610$ & $5 \times 10^{-2}$ & 6 & 360 & \\
1050 & $500-640$ & $5 \times 10^{-2}$ & 5 & 185 & This study \\
& $640-650$ & $5 \times 10^{-2}$ & 5 & 1160 & \\
$6061 / \mathrm{SiC}_{\mathrm{w}}$ & $560-600$ & $1.4 \times 10^{-1}$ & 3 & 774 & Ref. 4) \\
$6061 / \mathrm{Si}_{3} \mathrm{~N}_{4 \mathrm{w}}$ & $540-550$ & $1 \times 10^{-1}$ & 5 & 168 & Ref. 11) \\
& $560-590$ & $1 \times 10^{-1}$ & 2 & 1033 & \\
$2124 / \mathrm{Si}_{3} \mathrm{~N}_{4 \mathrm{p}}$ & $485-515$ & $1 \times 10^{-1}$ & 2 & 460 & Ref. 6) \\
5056 & $480-560$ & $1 \times 10^{-2}$ & 3 & 135 & Ref. 12) \\
& $615-620$ & $1 \times 10^{-1}$ & $1-3$ & 1653 &
\end{tabular}

where $D_{1}$ is the coefficient for lattice self-diffusion and

$$
\dot{\varepsilon}=5.6 \times 10^{8}\left(\frac{b D_{\mathrm{gb}}}{d^{3}}\right)\left(\frac{\sigma}{E}\right)^{2}
$$

where $D_{\mathrm{gb}}$ is the coefficient for grain boundary diffusion. It is apparent that both of these relationships have $n=2$ but the values of $p$ are either 2 or 3 for control by lattice diffusion or grain boundary diffusion, respectively.

In practice, eqs. (4) and (5) were derived for conditions where there is no threshold stress and no load transfer. Therefore, taking $\alpha=0$ and $\sigma_{\text {th }}=0$ in eq. (2) for the situation where lattice diffusion is rate-controlling, and substituting eq. (4) into eq. (2), it is possible to derive an expression for the appropriate value of $\mathrm{A}$ in eq. (2). This value is given by

$$
A=A_{1}=6.4 \times 10^{9} \frac{k T}{E b^{3}}
$$

where $A_{1}$ denotes the value associated with lattice diffusion. Similarly, eq. (5) may be substituted into eq. (2) to give the dimensionless constant associated with grain boundary diffusion, $A_{\mathrm{gb}}$. Taking $b=2.86 \times 10^{-10} \mathrm{~m}$ and the average testing temperature of $580^{\circ} \mathrm{C}$ for the $6061 / \mathrm{SiC}_{\mathrm{w}}$ composite, these values were estimated as $A_{1} \approx 6.6 \times 10^{7}$ and $A_{\mathrm{gb}} \approx 5.8 \times 10^{6}$, respectively. Therefore, eq. (2) reduces to either

$$
\dot{\varepsilon}=6.6 \times 10^{7}\left(\frac{D_{1} E b}{k T}\right)\left(\frac{b}{d}\right)^{2}\left(\frac{(1-\alpha)\left(\sigma-\sigma_{\mathrm{th}}\right)}{E}\right)^{2}
$$

for control by lattice diffusion or

$$
\dot{\varepsilon}=5.8 \times 10^{6}\left(\frac{D_{\mathrm{gb}} E b}{k T}\right)\left(\frac{b}{d}\right)^{3}\left(\frac{(1-\alpha)\left(\sigma-\sigma_{\mathrm{th}}\right)}{E}\right)^{2}
$$

for control by grain boundary diffusion.

Using eqs. (7) and (8), the individual values of $\alpha$ were estimated for each separate testing temperature. These values of $\alpha$ were $0.87,0.83,0.65$ and 0.50 when using eq. (7) for temperatures of $550,570,590$ and $610^{\circ} \mathrm{C}$, respectively, and they were 0.39 and 0.14 at 550 and $570^{\circ} \mathrm{C}$ and zero at the two highest testing temperatures when using eq. (8), as listed in Table 4. All of these values show that the magnitude of $\partial \alpha / \partial T$ is negative in eq. (3) but the latter results are more reasonable when using eq. (8) for grain boundary diffusion because there is no load transfer, and the value of $\alpha$ is there-
Table 4 Corrections incorporating the load transfer effect for the $6061 / \mathrm{SiC}_{\mathrm{w}}$ composite.

\begin{tabular}{ccccc}
\hline$T /{ }^{\circ} \mathrm{C}$ & $\alpha_{\text {lattice }}$ & $\alpha_{\mathrm{gb}}$ & $Q_{\mathrm{a}} / \mathrm{kJ} \mathrm{mol}^{-1}$ & $Q_{\mathrm{t}} / \mathrm{kJ} \mathrm{mol}^{-1}$ \\
\hline 550 & 0.87 & 0.39 & 195 & 70 \\
570 & 0.83 & 0.14 & 195 & 70 \\
590 & 0.65 & 0 & 600 & 595 \\
610 & 0.50 & 0 & 1027 & 1000 \\
\hline
\end{tabular}

fore zero, at temperatures above the onset of partial melting. By incorporating the value estimated for $\partial \alpha / \partial T$ into eq. (3), it is found that $Q_{\mathrm{t}} \approx 70 \mathrm{~kJ} \mathrm{~mol}^{-1}$ in the temperature range of $550-570^{\circ} \mathrm{C}$ (Table 4) and this value is close to the anticipated activation energy for grain boundary diffusion in $\mathrm{Al}$ $\left.\left(\sim 84 \mathrm{~kJ} \mathrm{~mol}^{-1}\right) .{ }^{5}\right)$ However, since $\alpha=0$ at 590 and $610^{\circ} \mathrm{C}$, the values of $Q_{\mathrm{t}}$ remain exceptionally high at these two temperatures, as seen in Table 4.

\subsubsection{Al-6061 and Al-1050 alloys}

Figures 9(b) and (c) show semi-logarithmic plots of $\sigma$ versus $1 / n R T$ for the two cast alloys: for both materials, the value of $n$ was taken as 5-6 from Figs. 2(b) and 8(b) and the strain rate was taken as $5 \times 10^{-2} \mathrm{~s}^{-1}$ to avoid any problem associated with power-law breakdown.

In Fig. 9(b) for the Al-6061 alloy, $Q_{\mathrm{a}}$ was estimated as $\sim 190 \mathrm{~kJ} \mathrm{~mol}^{-1}$ at temperatures of $550-570^{\circ} \mathrm{C}$ and $\sim 370 \mathrm{~kJ} \mathrm{~mol}^{-1}$ at temperatures of $590-610^{\circ} \mathrm{C}$, where the increase in $Q_{\mathrm{a}}$ occurs in the vicinity of the solidus temperature of $582^{\circ} \mathrm{C}$. When converted to the true activation energies using eq. (1), these values become $\sim 185$ and $\sim 360 \mathrm{~kJ} \mathrm{~mol}^{-1}$, respectively. In Fig. 9(c) for the Al-1050 alloy, $Q_{\mathrm{a}}$ is $\sim 190 \mathrm{~kJ} \mathrm{~mol}^{-1}$ below the solidus temperature of $646^{\circ} \mathrm{C}$ and $\sim 1180 \mathrm{~kJ} \mathrm{~mol}^{-1}$ above $T_{\mathrm{s}}$. Converting to the true activation energies using eq. (1), these values become $\sim 185$ and $\sim 1160 \mathrm{~kJ} \mathrm{~mol}^{-1}$, respectively. Thus, essentially identical values of $Q_{\mathrm{t}}\left(\sim 185 \mathrm{~kJ} \mathrm{~mol}^{-1}\right)$ are obtained at the lower temperatures for both cast alloys and these values are higher than the activation energy for self-diffusion in pure $\mathrm{Al}\left(\sim 142 \mathrm{~kJ} \mathrm{~mol}^{-1}\right)^{5)}$ but they are similar to the value $\left(\sim 210 \mathrm{~kJ} \mathrm{~mol}^{-1}\right)$ reported for high temperature deformation in a commercial purity aluminum alloy. ${ }^{25)}$ Both cast alloys exhibit exceptionally high values for $Q_{\mathrm{t}}$ at the higher testing temperatures where there is a liquid phase.

\subsection{The significance of a liquid phase}

An important result from this investigation is that all three materials have activation energies for flow which are $<200 \mathrm{~kJ} \mathrm{~mol}^{-1}$ at the lower temperatures where no liquid phase is present but there is an increase to exceptionally high values at temperatures above $T_{\mathrm{i}}$ or $T_{\mathrm{s}}$ with activation energies as high as $>1000 \mathrm{~kJ} \mathrm{~mol}^{-1}$ in the $6061 / \mathrm{SiC}_{\mathrm{w}}$ composite and the Al-1050 alloy. It is concluded that exceptionally high activation energies are a characteristic feature of flow in aluminum-based alloys at ultrahigh temperatures in the presence of a liquid phase and these high values are independent of the alloy system (whether Al-6061 or Al-1050), the grain size during testing (ranging from $\sim 2 \mu \mathrm{m}$ in the composite to $>100 \mu \mathrm{m}$ in Al-1050), whether HSR SP is observed $\left(6061 / \mathrm{SiC}_{\mathrm{w}}\right)$ or not observed (Al-6061 and Al-1050), whether the material is reinforced $\left(6061 / \mathrm{SiC}_{\mathrm{W}}\right)$ or unreinforced $(\mathrm{Al}-$ 
6061 and Al-1050) and the rate-controlling flow process at the lower testing temperatures (ranging from superplasticity and $n=2$ in $6061 / \mathrm{SiC}_{\mathrm{w}}$ to power-law creep and $n \approx 5$ in Al-6061 and Al-1050). These high values cannot be attributed solely to the effect of load transfer because there is no load transfer either in the $6061 / \mathrm{SiC}_{\mathrm{w}}$ composite at temperatures above $T_{\mathrm{i}}$ or in the two unreinforced alloys. Nevertheless, these high values are consistent with earlier observations on an $\mathrm{Al}-5 \% \mathrm{Mg}$ alloy tested in a semi-solid condition ${ }^{12)}$ and they demonstrate conclusively that exceptionally high activation energies are an inherent feature of flow in the presence of a small amount of discontinuous liquid immediately above the onset of partial melting. The addition of a liquid phase into the materials would induce a structure change, which would correspond to a change in thermodynamic states. Thus the detailed analyses in terms of kinetic creep mechanisms would not result in activation energy values that are physically meaningful.

Some conclusions can be reached concerning the significance of the liquid phase through inspection of Fig. 9. Thus, the activation energy in the commercial purity Al-1050 alloy increases only above $T_{\mathrm{s}}$ whereas in the Al-6061 alloy, where the presence of $\mathrm{Mg}$ and $\mathrm{Si}$ serve to lower the solidus temperature to $\sim 570-590^{\circ} \mathrm{C}$ depending on the local solute content, the activation energy begins to increase above $\sim 570^{\circ} \mathrm{C}$. This latter change is associated also with a decrease in the stress exponent to $\sim 1.3$ at the slowest strain rates, as shown in Fig. 2(b).

The results for the $6061 / \mathrm{SiC}_{\mathrm{w}}$ composite are generally in good agreement with the reported trends in most MMCs exhibiting HSR SP. ${ }^{9)}$ It has been suggested that a liquid phase is needed to relax the stress concentrations in order to achieve HSR SP and, conversely, no liquid phase is needed when there are no high stress concentrations. ${ }^{26)}$ It is possible to check this concept by noting that the local stress, $\sigma_{\mathrm{i}}$, created at the interfaces due to grain boundary sliding in particulate-reinforced composites is given by ${ }^{26)}$

$$
\sigma_{\mathrm{i}}=\frac{0.92 k T d_{\mathrm{p}} \dot{\varepsilon} d \Delta V}{\Omega D_{\mathrm{l}}\left(1+5 \frac{\delta D_{\mathrm{gb}}}{d_{\mathrm{p}} D_{\mathrm{l}}}\right)},
$$

where $d_{\mathrm{p}}$ is the size of the particulates, $\Delta V$ is the volume fraction of the reinforcement, $\Omega$ is the atomic volume and $\delta$ is the grain boundary width. For the $6061 / \mathrm{SiC}_{\mathrm{w}}$ composite, the whiskers are very long and spread through several grains. Therefore, it is reasonable to assume, as a first estimate, that $d_{\mathrm{p}}$ may be approximated by the average whisker diameter $(\sim 0.5 \mu \mathrm{m})$ so that, for temperatures from 590 to $610^{\circ} \mathrm{C}$ and at a strain rate of $1 \times 10^{-1} \mathrm{~s}^{-1}$, the values of $\sigma_{\mathrm{i}}$ are of the order of $\sim 70 \mathrm{MPa}$. These values are more than an order of magnitude higher than the measured flow stresses of $\sim 2-5 \mathrm{MPa}$ recorded in Fig. 2(a) for these test conditions. It is concluded, therefore, that the stress concentrations caused by grain boundary sliding in HSR SP may be relaxed through the presence of the liquid phase.

No attempt was made in this investigation to conduct experiments at even higher testing temperatures where there is a continuous liquid phase and it is anticipated that deformation will occur by liquid viscous flow with $n=1$ and a very low activation energy close to that for viscosity in molten alu- minum. On the contrary, the present experiments were extended to temperatures only slightly above $T_{\mathrm{i}}$ or $T_{\mathrm{s}}$ but they serve to demonstrate that, at least for the three materials used in these experiments, very high activation energies are a common feature at these high temperatures.

\section{Conclusion}

(1) Tensile tests were conducted at ultrahigh temperatures on three materials: an Al-6061 composite containing 20 vol\% SiC whiskers and unreinforced Al-6061 and Al-1050 alloys prepared by casting. High strain rate superplasticity was observed in the composite but not in the cast alloys.

(2) For all three materials, it is shown that the true activation energies for flow change from values of $<200 \mathrm{~kJ} \mathrm{~mol}^{-1}$ at the lower testing temperatures where there is no liquid phase to exceptionally high values at temperatures where a liquid phase is present: these values are up to $>1000 \mathrm{~kJ} \mathrm{~mol}^{-1}$ in the Al-6061 composite and the Al-1050 alloy.

(3) It is concluded that exceptionally high activation energies are an inherent feature of flow in materials containing a small amount of discontinuous liquid phase when tested at temperatures immediately above the onset of partial melting. The addition of a liquid phase into the materials would induce a structure change, which would correspond to a change in thermodynamic states. Thus the detailed analyses in terms of kinetic creep mechanisms would not result in activation energy values that are physically meaningful.

\section{Acknowledgements}

This work was supported by the National Science Council of ROC under Project No. NSC 87-2216-E-110-018. Some of the tensile testing was performed by one of the authors (BYL) during an appointment as Visiting Scholar at the University of Southern California.

\section{REFERENCES}

1) K. Higashi, M. Mabuchi and T. G. Langdon: ISIJ Intl. 36 (1996) 14231429.

2) A. Ball and M. M. Hutchison: Metal Sci. J. 3 (1969) 1-6.

3) T. G. Langdon: Acta Metall. Mater. 42 (1994) 2437-2443.

4) B. Q. Han and K. C. Chan: Scr. Mater. 36 (1997) 593-598.

5) H. J. Frost and M. F. Ashby: Deformation-Mechanism Maps, (Pergamon Press, Oxford, England, 1982) pp. 20-29.

6) H. Iwasaki and K. Higashi: Mater. Trans., JIM 41 (2000) 367-375.

7) J. Koike, M. Mabuchi and K. Higashi: J. Mater. Res. 10 (1995) 133-138.

8) J. Koike, M. Mabuchi and K. Higashi: Acta Mater. 43 (1995) 199-206.

9) K. Higashi and M. Mabuchi: Mater. Sci. Forum 233-234 (1997) 155160.

10) M. Mabuchi and K. Higashi: Scr. Mater. 34 (1996) 1893-1897.

11) M. Mabuchi, H. Iwasaki and K. Higashi: Acta Mater. 46 (1998) 53355343.

12) H. Iwasaki, T. Mori, M. Mabuchi and K. Higashi: Acta Mater. 46 (1998) 6351-6360

13) T. G. Nieh, R. Kaibyshev, F. Musin and D. R. Lesuer: Superplasticity and Superplastic Forming 1998, eds. A. K. Ghosh and T. R. Bieler, (TMS, Warrendale, PA, 1998) pp. 137-144.

14) Aluminum Standard and Data 1993, (The Aluminum Association, Washington, DC, 1993) pp. 39-40.

15) T. Imai, M. Mabuchi, Y. Tozawa and M. Yamada: J. Mater. Sci. Lett. 9 (1990) 255-257.

16) M. Mabuchi, K. Higashi, S. Tanimura, T. Imai and K. Kubo: Scr. Metall. 
Mater. 25 (1991) 1675-1680.

17) T. Imai, G. L’Esperance, B. D. Hong and S. Kojima: Scr. Metall. Mater. 33 (1995) 1333-1338.

18) Y. Li and T. G. Langdon: Mater. Sci. Tech. 15 (1999) 357-365.

19) R. Lagneborg and B. Bergman: Metal Sci. 10 (1976) 20-25.

20) Y. Li and T. G. Langdon: Scr. Mater. 36 (1997) 1457-1462.

21) Y. Li and T. G. Langdon: Acta Mater. 46 (1998) 3937-3948.
22) C. S. Liauo and J. C. Huang: Scr. Mater. 39 (1998) 873-879.

23) K.-T. Park and F. A. Mohamed: Metall. Mater. Trans. 26A (1995) 31193129.

24) O. D. Sherby and J. Wadsworth: Prog. Mater. Sci. 33 (1989) 169-221.

25) P. Olla and P. F. Virdis: Metall. Trans. 18A (1987) 293-301.

26) M. Mabuchi and K. Higashi: Acta Mater. 47 (1999) 1915-1922. 